\title{
Predictors of mortality in patients less than 50 years old with coronavirus disease 2019: a multicenter experience in Istanbul
}

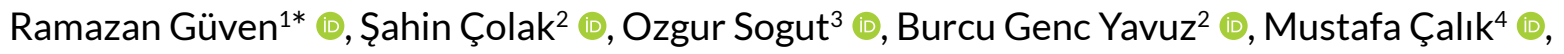

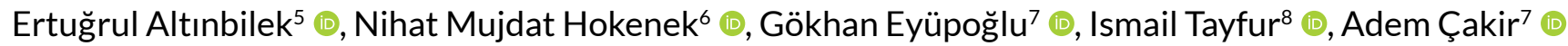

\begin{abstract}
SUMMARY
OBJECTIVE: The objectives of this study were to identify predictors of mortality in young adult patients with coronavirus disease 2019 and to assess the link between blood type and mortality in those patients.

METHODS: This multicenter retrospective study, which was conducted in seven training and research hospitals in Istanbul, involved young adults who aged $\geq 18$ and $<50$ years and hospitalized with coronavirus disease 2019.

RESULTS: Among 1,120 patients, confusion at admission ( $p<0.001$ ) and oxygen saturation ( $p<0.001$ ) were significantly predictive factors of mortality Blood type $O$ was significantly associated with mortality compared to those discharged from the hospital $(p<0.001)$. Among co-morbidities, the most reliable predictive factors were cerebral vascular disease $(p<0.001)$ and chronic renal failure $(p=0.010)$. Among laboratory parameters, high C-reactive protein $(p<0.001)$ and low albumin $(p<0.001)$ levels were predictors of mortality in young adult patients with coronavirus disease 2019. CONCLUSIONS: $\mathrm{SpO}_{2}$ at admission was the best predictor of mortality in young adult patients with coronavirus disease 2019. The mortality rate was increased by cerebral vascular disease and chronic renal failure. Also, high C-reactive protein and low albumin levels were predictive factors of mortality. Moreover, blood type O was associated with a higher mortality rate than the other types.
\end{abstract}

KEYWORDS: Adult. COVID-19. Mortality.

\section{INTRODUCTION}

\section{Background}

Coronavirus disease 2019 (COVID-19), caused by the highly contagious severe acute respiratory syndrome coronavirus-2 (SARS-CoV-2), was first identified in Wuhan, China, in December 2019, and it has become the pandemic of the last century. SARS-CoV-2 has infected around 100 million people, 2 million of whom have died ${ }^{1}$.

In the early stages of the pandemic, it was thought that COVID-19 affected only older adults and killed only geriatric patients. Therefore, most COVID-19 studies involved patients of advanced age. Indeed, the mortality rate is higher in patients with chronic medical conditions, such as diabetes mellitus (DM) and hypertension $(\mathrm{HT})^{2}$. Moreover, high D-dimer and ferritin levels are predictive factors of mortality ${ }^{3}$. During the early days of the pandemic, the relationship between $\mathrm{ABO}$ blood type and COVID-19 susceptibility and mortality was much discussed ${ }^{4}$. As the pandemic progressed, COVID-19 deaths occurred in younger patients ${ }^{5}$. However, few studies have examined predictive factors of mortality, including laboratory findings, in younger patients.

In this multicenter study, we examined predictors of mortality in terms of demographics, co-morbidities, and laboratory findings in young adult patients with COVID-19 and evaluated the link between blood type and mortality.

\section{METHODS}

\section{Study design and setting}

This multicenter, retrospective, observational study was carried out between March 20, 2020 and June 30, 2020. Data were

\footnotetext{
${ }^{1}$ University of Health Sciences, Kanuni Sultan Suleeyman Training and Research Hospital, Department of Emergency Medicine - Istanbul, Turkey. 2University of Health Sciences, Haydarpasa Numune Training and Research Hospital, Department of Emergency Medicine - Istanbul, Turkey. ${ }^{3}$ University of Health Sciences, Haseki Training and Research Hospital, Department of Emergency Medicine - Istanbul, Turkey. ${ }^{4}$ University of Health Sciences, Gaziosmanpasa Training and Research Hospital, Department of Emergency Medicine - Istanbul, Turkey. ${ }^{5}$ University of Health Sciences, Sisli Etfal Training and Research Hospital, Department of Emergency Medicine - Istanbul, Turkey. 'University of Health Sciences, Kartal Dr. Lutfi Kirdar Training and Research Hospital, Department of Emergency Medicine - Istanbul, Turkey. 7 University of Health Sciences, Basaksehir Cam and Sakura City Hospital, Department of Emergency Medicine - Istanbul, Turkey. ${ }^{8}$ University of Health Sciences, Sancaktepe Sehit Prof. Dr. Ilhan Varank Training and Research Hospital, Department of Emergency Medicine - Istanbul, Turkey. ${ }^{*}$ Corresponding author: drramazanguven@gmail.com

Conflicts of interest: the authors declare there is no conflicts of interest. Funding: This study was supported by the Advisory Board on Coronavirus Research of the Turkish Ministry of Health.

Received on October 19, 2021. Accepted on December 05, 2021.
} 
collected from seven research and training hospitals in Istanbul, Turkey. This study enrolled young adult patients (aged $\geq 18$ and $<50$ years) who were admitted to the pandemic ward or pandemic intensive care unit with signs of COVID-19 pneumonia on chest computed tomography (CT) or positive in polymerase chain reaction (PCR) test. Admission decisions were made according to the COVID-19 guidelines ${ }^{6}$ of The Coronavirus Scientific Advisory Board of the General Directorate of Public Health, Turkish Ministry of Health. According to these guidelines, patients with mild-moderate pneumonia, those with mild-moderate pneumonia with poor prognostic factors in laboratory tests at admission, or patients with severe pneumonia are hospitalized.

\section{Data collection}

The total number of patients admitted to emergency departments of the centers during the study period was 513,168, among whom 34,304 were hospitalized for any diagnosis. We identified 1,629 young adult patients with COVID-19.

Data were collected by searching for U06.0 and U07.3 International Classification of Disease codes in the hospitals' automation systems. We assessed patients' demographics, vital signs at admission, complaints at admission, comorbidities, result of PCR test, blood type, laboratory parameters, hematological findings, and biochemical findings.

This study was approved by the Institutional Review Board of XXX Research and Training Hospital, Istanbul, Turkey (no. 2020-KSSH-1331 and clinicaltrials.gov ID: NCT04479137).

\section{Statistical analysis}

Statistical analysis was performed by using MedCalc Statistical Software version 19.4.1. Patient data are expressed as medians for normally distributed variables and as percentages for categorical variables. The normality of the distribution of continuous variables was examined using the Kolmogorov-Smirnov test. Between-group comparisons of normally distributed parameters were conducted using Student's t-test; the Mann-Whitney U-test was applied for non-normally distributed parameters. Categorical variables were analyzed using chi-square test or Fisher's test.

\section{RESULTS}

Data from 1,120 patients with COVID-19 were evaluated. Among them, $60.4 \%(\mathrm{n}=677)$ were males with a median (quartiles) age of $42.0(35.0-46.0)$ years. Of the patients, $88.6 \%$ were discharged (survivors) and $11.4 \%(\mathrm{n}=128)$ were died (non-survivors). The distributions of demographic parameters, complaints at admission, and co-morbidities in survivors and non-survivors are shown in Table 1 . There were significant differences between non-survivors and survivors in age, $\mathrm{SpO}_{2}$ at admission, confusion, fatigue, HT, DM, cerebrovascular disease (CVD), and chronic renal failure (CRF) $(\mathrm{p}<0.001)$. Based on age categories, i.e., $18-29$, 30-39, and $40-49$ years, $69.5 \%(n=89)$ of non-survivors were in the age group of 40-49 years. Of the total deaths, $21.9 \%(n=28)$ were in the age group of 30-39 years, and $8.6 \%(n=11)$ were in the age group of $18-29$ years. Among 489 patients, the frequency of blood type $\mathrm{O}$ was significantly higher among non-survivors $(\mathrm{p}=0.010)$. The distribution of blood groups by age and survival is shown in Figure 1 .

Laboratory parameters at admission are listed in Table 1. The lymphocyte, thrombocyte, calcium, and albumin values were lower, and the lactate dehydrogenase (LDH), blood urea nitrogen (BUN), ferritin, D-dimer, and CRP levels were higher in non-survivors than in survivors. Univariate and multivariate regression analyses were performed to identify predictors of mortality (Table 2). Model 1 comprised age, vital signs at admission, and complaints at admission, model 2 added co-morbidities and blood type $\mathrm{O}$, and model 3 added laboratory parameters. A multivariate regression analysis showed that confusion $(\mathrm{p}<0.001)$ and $\mathrm{SpO}_{2}$ at admission $(\mathrm{p}<0.001)$ were reliable predictors of mortality in model 1 . In model 2, CVD $(p<0.001)$, CRF $(p=0.010)$, and blood type $O(p=0.014)$; and in model 3, platelet count $(\mathrm{p}=0.022)$, albumin $(\mathrm{p}<0.001)$, BUN $(\mathrm{p}=0.005)$, and CRP $(\mathrm{p}<0.001)$ were predictive factors of mortality in young adult patients with COVID-19.

\section{DISCUSSION}

In this large multicenter study, we evaluated the factors associated with mortality in young adult patients with COVID-19. In this study, instead of PCR, we used chest CT because of its higher sensitivity. All patients included in the study had chest CT findings indicative of COVID-19. The key findings were as follows: (1) age was associated with mortality, and the majority of non-survivors (69.5\%) were 40-50 years of age. (2) Confusion at admission, $\mathrm{SpO}_{2}$ at admission, CVD, and CRF were independently predictive factors of mortality. (3) Non-survivors had a higher rate of blood type O (43.9\%) than survivors. (4) The albumin and CRP levels were predictive factors of mortality.

Advanced age is a predictor of mortality in patients with COVID-197. We obtained similar results and the mortality rate increased as patients approached 50 years. In a study of patients with COVID-19 who aged 18-34 years, male sex was a risk 
Table 1. Characteristics of the patients and laboratory results.

\begin{tabular}{|c|c|c|c|}
\hline & Non-survivors $(n=128)$ & Survivors (n=992) & p-value \\
\hline Male $[\%(n)]$ & $62.5(80)$ & $60.2(597)$ & 0.614 \\
\hline Age (years) & $42.5 \pm 6.1$ & $39.0 \pm 8.4$ & $<0.001$ \\
\hline Admission systolic blood pressure $(\mathrm{mmHg})$ & $125.0(110.0-140.0)$ & $127.0(110.0-140.0)$ & 0.295 \\
\hline Admission diastolic blood pressure $(\mathrm{mmHg})$ & $70.0(63.2-80.0)$ & $70.0(65.0-80.0)$ & 0.350 \\
\hline Admission oxygen saturation (\%) & $92.0(88.0-95.0)$ & $97.0(95.0-98.0)$ & $<0.001$ \\
\hline Admission heart rate (BPM) & $92.0(78.0-109.0)$ & $87.0(76.0-92.0)$ & 0.004 \\
\hline Admission fever $\left({ }^{\circ} \mathrm{C}\right)$ & $37.0(36.0-37.5)$ & $36.8(36.5-37.5)$ & 0.349 \\
\hline Cough $[\%(n)]$ & $50.8(63)$ & $64.8(593)$ & 0.002 \\
\hline Fever $[\%(n)]$ & $44.3(54)$ & $41.6(364)$ & 0.584 \\
\hline Nausea and vomiting [\%(n)] & $15.6(19)$ & $9.5(85)$ & 0.038 \\
\hline Impaired consciousness [\%(n)] & $70.5(86)$ & $29.4(267)$ & $<0.001$ \\
\hline Sore throat [\%(n)] & $4.2(5)$ & $10.3(92)$ & 0.032 \\
\hline Weakness [\%(n)] & $43.8(53)$ & $27.4(244)$ & $<0.001$ \\
\hline Chest pain $[\%(n)]$ & $12.1(15)$ & $6.7(59)$ & 0.030 \\
\hline $\mathrm{HT}[\%(n)]$ & $22.6(28)$ & $9.4(83)$ & $<0.001$ \\
\hline $\mathrm{DM}[\%(n)]$ & $21.8(27)$ & $10.2(90)$ & $<0.001$ \\
\hline CAD $[\%(n)]$ & $6.5(8)$ & $2.5(22)$ & 0.015 \\
\hline CVD $[\%(n)]$ & $9.7(12)$ & $0.8(7)$ & $<0.001$ \\
\hline COPD/Asthma [\%(n)] & $8.1(10)$ & $5.1(45)$ & 0.172 \\
\hline CRF $[\%(n)]$ & $10.3(12)$ & $1.9(15)$ & $<0.001$ \\
\hline WBC count $\left(\times 10^{3}\right.$ per $\left.\mu \mathrm{L}\right)$ & $5.85(3.3-9.5)$ & $6.25(4.7-10.4)$ & 0.668 \\
\hline Platelet count ( $\times 10^{3}$ per $\left.\mu \mathrm{L}\right)$ & $160.0(119.0-204.0)$ & $206.0(164.0-239.0)$ & $<0.001$ \\
\hline Neutrophil count $\left(\times 10^{3}\right.$ per $\left.\mu \mathrm{L}\right)$ & $4.38(2.5-6.4)$ & $4.44(3.3-8.1)$ & 0.092 \\
\hline Lymphocyte count $\left(\times 10^{3}\right.$ per $\left.\mu \mathrm{L}\right)$ & $0.85(0.5-1.1)$ & $1.3(1.0-1.9)$ & $<0.001$ \\
\hline BUN (mg/dL) & $16.5(11.2-35.4)$ & $12.1(9.3-15.4)$ & $<0.001$ \\
\hline $\mathrm{LDH}(\mathrm{U} / \mathrm{L})$ & $382.5(280.7-528.2)$ & $312.0(235.0-366.0)$ & $<0.001$ \\
\hline Albumin (g/L) & $30.0(24.0-33.0)$ & $36.0(32.0-40.0)$ & $<0.001$ \\
\hline $\mathrm{CRP}(\mathrm{mg} / \mathrm{L})$ & $95.6(55.1-203.6)$ & $51.8(27.1-83.6)$ & $<0.001$ \\
\hline Ferritin (ng/mL) & $617.6(371.9-1497.0)$ & $283.3(120.8-629.0)$ & $<0.001$ \\
\hline D-Dimer (mg/L) & $1.64(0.7-3.1)$ & $0.78(0.4-1.4)$ & $<0.001$ \\
\hline Calcium (mg/dL) & $8.3(7.7-8.4)$ & $8.5(8.0-8.9)$ & $<0.001$ \\
\hline
\end{tabular}

Bold indicates significance at $p<0.005$. Fisher's exact test. Data are means \pm standard deviation, medians (quartiles), and percentages for categorical variables.

factor for mortality and ventilation ${ }^{8}$. In contrast, we found no significant gender difference between survivors and non-survivors. COVID-19 can cause severe lung pathology and reduce the $\mathrm{SpO}_{2}$; indeed, $\mathrm{SpO}_{2}$ at admission and $\mathrm{HR}$ were predictors of mortality, as reported by Sands et $\mathrm{al}^{9}$.

The COVID-19 mortality rate is higher in patients with co-morbidities, such as DM and HT. Here, the mortality rate was significantly higher in patients with HT, DM, [cardiovascular disease (CAD)], CVD, and CRF; the latter two parameters were reliable predictors of mortality in the multivariate regression analysis. It is hypothesized that COVID-19 causes coagulopathy and thrombosis and, therefore, aggravates $\mathrm{CVD}^{10}$.

Siepmann et al. reported that COVID-19 is more likely to occur and to be more severe in patients with $\mathrm{CVD}^{11}$. Together with our results, this shows that COVID-19 and coagulopathy frequently co-occur. In the multivariate regression 


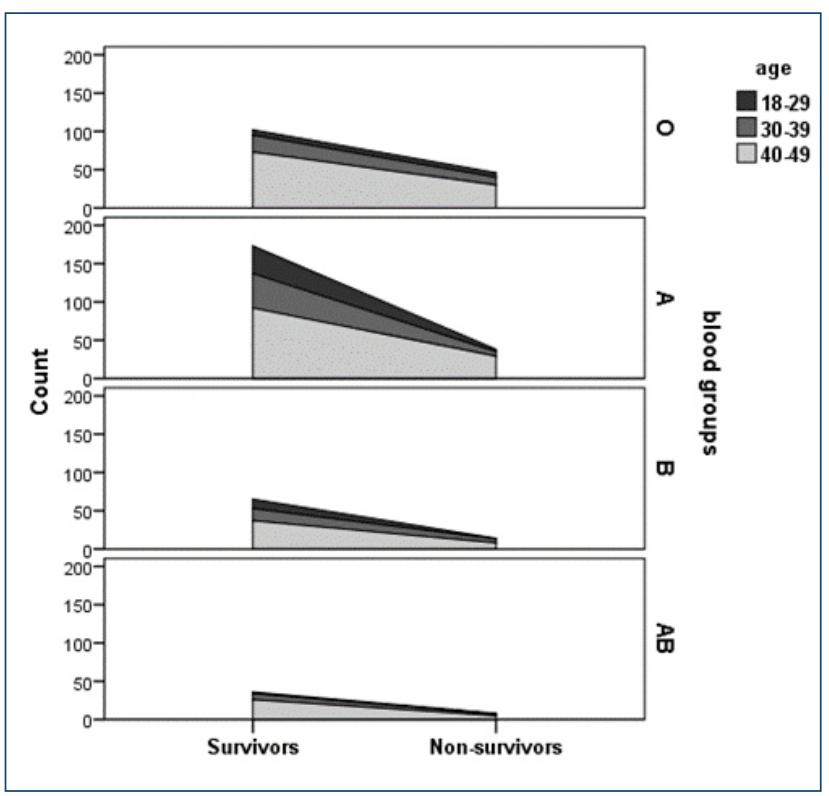

Figure 1. Distribution of blood groups by age and survival. analysis, CRF was a more predictive factor of mortality than DM and HT. This study included 27 patients with CRF, 44.4\% of whom died, suggesting that the mortality rate of COVID-19 is increased by CRF in younger patients. The International Society of Nephrology guidelines recommend that patients with CRF take stringent measures to prevent COVID-19 ${ }^{12}$.

The effect of $\mathrm{ABO}$ blood type and Rh factor on mortality has been debated. Zietz et al. reported that among 112 patients, the infection rate was higher for non-O types, and the mortality rate was higher for types $\mathrm{AB}$ and $\mathrm{B}$ compared with type $\mathrm{O}^{13}$. Similarly, Ray et al. reported that mortality from SARS-CoV-2 was lower among patients with blood type $\mathrm{O}^{14}$. Most studies of the relationship between COVID-19 severity and blood type concluded that the risk of severe disease is high for type $\mathrm{A}$ and low for type $\mathrm{O}^{15}$. Research on the relationship between COVID-19 and blood type is based on the similarity of genetic variants linked to the immune system and blood type ${ }^{16}$. In some studies in the literature, it was determined that there was no relationship between

Table 2. Regression analysis models for identifying predictors of mortality.

\begin{tabular}{|c|c|c|c|c|}
\hline \multirow{2}{*}{ Variable } & \multicolumn{2}{|c|}{ Univariate } & \multicolumn{2}{|c|}{ Multivariate } \\
\hline & OR $(95 \% \mathrm{Cl})$ & p-value & Adjusted OR (95\%CI) & p-value \\
\hline \multicolumn{5}{|l|}{ Model 1} \\
\hline Age (years) & $1.051(1.023-1.078)$ & $<0.001$ & $1.048(1.011-1.087)$ & 0.011 \\
\hline Admission heart rate (BPM) & $1.007(0.997-1.018)$ & 0.170 & & \\
\hline Cough & $1.783(1.223-2.600)$ & 0.003 & $1.284(0.753-2.190)$ & 0.359 \\
\hline Impaired consciousness & $36.583(16.338-81.915)$ & $<0.001$ & $36.089(10.925-119.212)$ & $<0.001$ \\
\hline Admission oxygen saturation (\%) & $0.736(0.691-0.784)$ & $<0.001$ & $0.748(0.697-0.802)$ & $<0.001$ \\
\hline \multicolumn{5}{|l|}{ Model 2} \\
\hline DM & $2.462(1.525-3.974)$ & $<0.001$ & $1.428(0.716-2.850)$ & 0.312 \\
\hline HT & $1.250(0.348-4.486)$ & $<0.001$ & $1.672(0.858-3.257)$ & 0.131 \\
\hline $\mathrm{KAH}$ & $2.702(1.176-6.210)$ & 0.019 & $1.225(0.360-4.158)$ & 0.745 \\
\hline CVD & $13.408(5.172-34.762)$ & $<0.001$ & $7.726(2.167-27.554)$ & $<0.001$ \\
\hline CRF & $5.862(2.670-12.867)$ & $<0.001$ & $3.199(1.317-7.771)$ & 0.010 \\
\hline O blood group & $2.084(1.335-3.254)$ & 0.001 & $1.847(1.135-3.005)$ & 0.014 \\
\hline \multicolumn{5}{|l|}{ Model 3} \\
\hline Platelet count $\left(\times 10^{3}\right.$ per $\left.\mu \mathrm{L}\right)$ & $0.994(0.991-0.997)$ & $<0.001$ & $0.993(0.986-0.999)$ & 0.022 \\
\hline Lymphocyte count ( $\times 10^{3}$ per $\left.\mu \mathrm{L}\right)$ & $0.745(0.600-0.925)$ & 0.008 & $1.375(0.770-2.454)$ & 0.281 \\
\hline Albumin (g/L) & $0.963(0.940-0.987)$ & 0.003 & $0.060(0.160-0.224)$ & $<0.001$ \\
\hline $\mathrm{BUN}(\mathrm{mg} / \mathrm{dL})$ & $1.015(1.008-1.022)$ & $<0.001$ & $1.055(1.016-1.094)$ & 0.005 \\
\hline $\mathrm{LDH}(\mathrm{U} / \mathrm{L})$ & $1.007(1.005-1.009)$ & $<0.001$ & $1.003(1.000-1.006)$ & 0.093 \\
\hline Calcium (mg/dL) & $0.649(0.487-0.866)$ & 0.003 & $1.120(0454-2.766)$ & 0.805 \\
\hline $\mathrm{CRP}(\mathrm{mg} / \mathrm{L})$ & $1.001(1.013-1.016)$ & $<0.001$ & $1.012(1.006-1.019)$ & $<0.001$ \\
\hline Ferritin & $1.134(1.061-1.211)$ & $<0.001$ & $1.005(0.926-1.090)$ & 0.913 \\
\hline $\mathrm{D}$-Dimer (mg/L) & $1.362(1.203-1.543)$ & $<0.001$ & $0.996(0.893-1.112)$ & 0.948 \\
\hline
\end{tabular}

Bold indicates significance at $p<0.005$. 
ABO blood group and COVID-195,17. In contrast, Solmaz et al. reported that blood type $\mathrm{O}$ protects against COVID- $19^{18}$. In this study, blood type $\mathrm{O}$ was associated with mortality among 489 patients and was a predictive factor of mortality in model 2.

Laboratory tests are typically performed to determine the severity of COVID-19. In Turkey, the Ministry of Health guidelines recommend considering the ferritin, lymphocytes, D-dimer, and CRP values when making decisions on hospitalization and treatment. Among middle-aged patients, a high D-dimer $(>1 \mu \mathrm{g} / \mathrm{mL})$ level and low albumin level were risk factors for severe COVID-196. CRP, an acute-phase reactant, is an indicator of COVID-19 severity ${ }^{19}$, as well as for other viral respiratory diseases, e.g., severe acute respiratory syndrome and Middle East respiratory syndrome ${ }^{20,21}$. In model 3, a high CRP level, hypoalbuminemia, thrombocytopenia, and a high BUN value were predictive factors of mortality, as well as of the severity of COVID-19 in young adult patients.

\section{REFERENCES}

1. Huang C, Wang Y, Li X, Ren L, Zhao J, Hu Y, et al. Clinical features of patients infected with 2019 novel coronavirus in Wuhan, China. Lancet. 2020;395 (10223):497-506. https://doi.org/10.1016/ S0140-6736(20)30183-5

2. Mueller AL, McNamara MS, Sinclair DA. Why does COVID-19 disproportionately affect older people? Aging (Albany NY). 2020;12(10):9959-81. https://doi.org/10.18632/aging.103344

3. Zhou F, Yu T, Du R, Fan G, Liu Y, Liu Z, et al. Clinical course and risk factors for mortality of adult inpatients with COVID-19 in Wuhan, China: a retrospective cohortstudy. Lancet. 2020;395(10229):105462. https://doi.org/10.1016/S0140-6736(20)30566-3

4. Latz CA, DeCarlo C, Boitano L, Png CYM, Patell R, Conrad MF, et al. Blood type and outcomes in patients with COVID-19. Ann Hematol. 2020;99(9):2113-8. https://doi.org/10.1007/s00277020-04169-1

5. Ioannidis JPA, Axfors C, Contopoulos-Ioannidis DG. Populationlevel COVID-19 mortality risk for non-elderly individuals overall and for non-elderly individuals without underlying diseases in pandemic epicenters. Environ Res. 2020;188:109890. https:// doi.org/10.1016/j.envres.2020.109890

6. Scientific Advisory Board Republic of Turkey Ministry of Health. SARS-CoV-2 infection: general information, epidemiology and diagnosis April 21, 2020 [cited on 2020 December 25]. Available from: https://covid19bilgi.saglik.gov.tr/depo/Sunumlar/COVID19-Epidemiyoloji-Tani-Tedavi.pdf.

7. Imam Z, Odish F, Gill I, O'Connor D, Armstrong J, Vanood A, et al. Older age and comorbidity are independent mortality predictors in a large cohort of 1305 COVID-19 patients in Michigan, United States. J Intern Med. 2020;288(4):469-76. https://doi.org/10.1111/ joim.13119

8. Cunningham JW, Vaduganathan M, Claggett BL, Jering KS, Bhatt AS, Rosenthal $\mathrm{N}$, et al. Clinical outcomes in young US adults hospitalized with COVID-19. JAMA Intern Med. 2020.181(3):379-81. https:// doi.org/10.1001/jamainternmed.2020.5313

9. Sands KE, Wenzel RP, McLean LE, Korwek KM, Roach JD, Miller $\mathrm{KM}$, et al. Patient characteristics and admitting vital signs associated

\section{CONCLUSIONS}

$\mathrm{SpO}_{2}$ at admission is a reliable predictor of mortality in young adult patients who hospitalized with COVID-19 and so may be useful for triaging such patients at admission. Among co-morbidities, CVD and CRF were more predictive factors of mortality than DM and HT. In addition, blood type $\mathrm{O}$, a high CRP level, and a low albumin level were predictive factors of mortality in young adult patients with COVID-19.

\section{AUTHORS' CONTRIBUTIONS}

RG: Conceptualization, Data curation. ŞÇ: Formal Analysis, Funding acquisition. BGY: Investigation, Methodology. MÇ: Project administration, Resources. EA: Software. NMH: Supervision, Validation. GE: Visualization. İT: Writing - original draft. AÇ: Writing - review \& editing.

with coronavirus disease 2019 (COVID-19)-related mortality among patients admitted with noncritical illness. Infect Contro Hosp Epidemiol. 2021. 42(4):399-405. https://doi.org/10.1017/ ice. 2020.461

10. Xu J, Xiao W, Liang X, Zhang P, Shi L, Wang Y, et al. The association of cerebrovascular disease with adverse outcomes in covid-19 patients: a meta-analysis based on adjusted effect estimates. J Stroke Cerebrovasc Dis. 29(11):105283. https://doi.org/10.1016/j. jstrokecerebrovasdis.2020.105283

11. Siepmann T, Sedghi A, Barlinn J, With K, Mirow L, Wolz M, et al. Association of history of cerebrovascular disease with severity of COVID-19. J Neurol. 2021;268(3):773-84. https://doi.org/10.1007/ s00415-020-10121-0

12. Kliger AS, Silberzweig J. Mitigating risk of COVID-19 in dialysis facilities. Clin J Am Soc Nephrol. 2020;15(5):707-9. https://doi. org/10.2215/CJN.03340320

13. Zietz M, Zucker J, Tatonetti NP. Associations between blood type and COVID-19 infection, intubation, and death. Nat Commun. 2020;11(1):5761. https://doi.org/10.1038/s41467-020-19623-x

14. Ray JG, Schull MJ, Vermeulen MJ, Park AL. Association between $A B O$ and Rh blood groups and SARS-Cov-2 infection or severe COVID-19 illness: a population-based cohort study. Ann Intern Med. 2021. 174(3):308-15. https://doi.org/10.7326/M20-4511

15. Zhao J, Yang Y, Huang H, Li D, Gu D, Lu X, et al. Relationship between the ABO blood group and the coronavirus disease 2019 (COVID-19) susceptibility. Clin Infect Dis. 2021;73(2):328-31. https://doi.org/10.1093/cid/ciaa1150

16. The Severe Covid-19 GWAS Group. Genomewide association study of severe Covid-19 with respiratory failure. N Engl J Med. 2020;383:1522-34. https://doi.org/10.1056/NEJMoa2020283

17. Arac E, Solmaz I, Akkoc H, Donmezdil S, Karahan Z, Kaya S, et al. Association between the Rh blood group and the Covid-19 susceptibility. Int J Hematol Oncol. 2020; 30(2):81-6. https://doi. org/10.4999/uhod.204247

18. Solmaz I, Araç S. ABO blood groups in COVID-19 patients; crosssectional study. Int J Clin Pract. 2021;75(4):e13927. https://doi. org/10.1111/ijcp.13927 
19. Sharifpour M, Rangaraju S, Liu M, Alabyad D, Nahab FB, CreelBulos CM, et al. C-Reactive protein as a prognostic indicator in hospitalized patients with COVID-19. PLoS One. 2020;15(11): e0242400. https://doi.org/10.1371/journal.pone.0242400

20. Wang JT, Sheng WH, Fang CT, Chen YC, Wang JL, Yu CJ, et al. Clinical manifestations, laboratory findings, and treatment outcomes of SARS patients. Emerg Infect Dis. 2004;10(5):818-24. https:// doi.org/10.3201/eid1005.030640

21. Ko JH, Park GE, Lee JY, Lee JY, Cho SY, Ha YE, et al. Predictive factors for pneumonia development and progression to respiratory failure in MERS-CoV infected patients. J Infect. 2016;73(5):468-75. https://doi.org/10.1016/j.jinf.2016.08.005 